\title{
Awareness on Birth Preparedness and Complication Readiness Among Antenatal Care Clients in Federal Police Referral Hospital Addis Ababa, Ethiopia
}

\author{
Seble Tiku \\ Police Medical Professional Training Institute, Ethiopia Police University College, Sendafa, Ethiopia
}

Email address:

tikuseble@yahoo.com

\section{To cite this article:}

Seble Tiku. Awareness on Birth Preparedness and Complication Readiness Among Antenatal Care Clients in Federal Police Referral Hospital Addis Ababa, Ethiopia. American Journal of Health Research. Vol. 3, No. 6, 2015, pp. 362-367. doi: 10.11648/j.ajhr.20150306.18

\begin{abstract}
Birth-preparedness and complication readiness is a comprehensive strategy aimed at promoting the timely utilization of skilled maternal and neonatal health care and encouraging women, households and communities to make arrangements. This paper aimed to assess knowledge and practices on birth preparedness and complication readiness and related factors among antenatal clients in Federal Police Referral Hospital. Institutional based cross-Sectional study was conducted on 224 sampled pregnant women from September 14, 2014- October, 242014 who were attending Ante Natal Care in Federal Referral Police Hospital, Addis Ababa. Data was analyzed using SPSS version 20. Different rates, as well as relevant associations were computed to see statistical significant. P-value less than 0.05 was taken as a cut of point to declare significant association. Multiple logistic regression analysis was also done to control for possible confounding variables. In this study the proportion of respondents considered as knowledgeable for key dangerous signs were 152(67.8\%), 140 (62.1\%), 118 (52.2\%) during pregnancy, delivery, and postpartum respectively About 126(56.3\%) of the women were considered as prepared for birth and its complication. Maternal age of less than 20 years $(\mathrm{COR}=3.5,95 \% \mathrm{CI}: 1.07,11.66)$. Mothers who knew the key danger sign of pregnancy, child birth andpost-partum were almost three times more likely to be prepared for birth and its complications than mothers who didn't know $(\mathrm{COR}=2.61,95 \% \mathrm{CI}: 1.47,4.65)$; $(\mathrm{COR}=2.72,95 \% \mathrm{CI}: 1.56,4.74)$ and $(\mathrm{COR}=2.66,95 \% \mathrm{CI}$ : $1.54,4.53)$ respectively. When the age of the client from socio demographic variables; knowledge on key danger signs of pregnancy, labor and post-partum were adjusted no one significantly associated with birth preparedness and complication readiness. In this study about $56.3 \%$ women were prepared for birth and its complication which is relatively fair. Knowledge of key dangers signs of pregnancy, labor and delivery and postpartum were found to be the main factors affecting birth preparedness and complication readiness. Improving ANC education on $\mathrm{BP} / \mathrm{CR}$, giving special emphasis to comprehensive knowledge of key danger signs is recommended.
\end{abstract}

Keywords: Birth-Preparedness, Complication Readiness, Labor, Childbirth

\section{Introduction}

Globally, there were an estimated 289, 000 maternal deaths in 2013, a decline of $45 \%$ from 1990. The sub-Saharan Africa region alone accounted for $62 \%$ (179, 000) of global deaths followed by Southern Asia at 24\% (69, 000). Maternal mortality is a substantial burden in developing countries. Around $80 \%$ of all maternal deaths are the result of direct obstetric complications: hemorrhage $25 \%$, sepsis $15 \%$, unsafe abortion $13 \%$, eclampsia $12 \%$, and obstructed labor $8 \%[1,2]$.

In Ethiopia according to Ethiopian Demographic and
Health Survey report of 2011 (EDHS 2011), the maternal mortality ratio was 676 maternal deaths per 100,000 live births which had no significant difference from those reported in the 2005 EDHS and 2000 EDHS. Direct obstetric complication accounts for $85 \%$ of the deaths. It includes abortion $32 \%$, obstructed labor $22 \%$, sepsis $12 \%$, and hemorrhage $10 \%$ and hypertension $9 \%$, primarily due to frequency of adolescent pregnancy combined with neglected prolonged labor. Most of these deaths are preventable when there is access to adequate reproductive health services, equipment, supplies and skilled healthcare workers [1, 3-5].

Improving maternal mortality has received recognition at a global level as evidenced by the inclusion of reducing 
maternal health in the Millennium Development Goals (MDG). In MDG 5, countries are committed to reducing the maternal mortality ratio by three quarters between 1990 and 2015. Following this commitment, Ethiopia is expected to reduce maternal mortality in 2015 to 267 maternal deaths per 100,000 live births $[5,6]$.

Emergency management of obstetric service is necessary if maternal mortality is to be reduced, they may not be sufficient. Even when Emergency management of obstetric Service is functioning well, Women with Obstetric Complication face a variety of barriers in using them. Anything that cause delay in getting treatment may cost women's life. These delays can be prevented by Birth preparedness and complication readiness $(\mathrm{BP} / \mathrm{CR})$ allows a pregnant women and her family to plan ahead, so that they can have safe and healthy pregnancy and delivery [7].

Birth - preparedness and complication readiness is a comprehensive strategy aimed at promoting the timely utilization of skilled maternal and neonatal health care and encouraging women, households and communities to make arrangements. The key elements includes: knowledge of danger signs during pregnancy, labor and post-partum: plan for where to give birth: plan for a birth attendant: plan for transportation and plan for saving money. In addition, a potential blood donor and a decision maker need to be identified. In sum, at the demand level, BP/CR promotes the use of a skilled provider at birth through increasing demand and improving access. Birth preparedness and complication readiness also reduces delays in receiving appropriate care. It calls on providers and facilities to be prepared to attend births and ready to treat complications. This is because every pregnant woman faces the risk of sudden, unpredictable complications that could end in death or injury to herself or to her infant [7-9].

In many societies in the world, cultural beliefs and lack of awareness inhibit preparation in advance for delivery and expected baby. Since no action is taken prior to the delivery, the family tries to act only when labor begins. The majority of pregnant women and their families do not know how to recognize the danger signs of complications. When complications occur, the unprepared family will waste a great deal of time in recognizing the problem, getting organized, getting money, finding transport and reaching the appropriate referral facility these delays can cause maternal death [8].

Awareness of the danger signs of obstetric complications among pregnant women and in their communities is the first step to accept appropriate and timely referral to essential obstetric and newborn care, this, reducing the first and second phases of delay. The danger signs occurring during pregnancy are predictive of poor outcome rather than historic risk factors. The time required to make arrangements, which could have been made prior to the emergency, may define the line between survival and mortality [8].

According to EDHS 2011, among women who were informed of signs of pregnancy complications at an Ante Natal Care (ANC) visit for their last live birth, almost half
(48\%) were informed of abdominal pain as a sign of pregnancy complications. More than one-third (36\%) were informed of severe headache, one-fourth (25\%) were informed of vaginal bleeding, and about one-fifth (22\%) were informed of vaginal gush or fluid as signs of pregnancy complications. Fourteen percent of women were informed of fever, and $7 \%$ were informed of blurred vision as possible signs of pregnancy complications [3].

The BP/CR tool is intended for use as both a programming and an advocacy tool by communities, health service providers, and health system administrators and planners. Structured as a matrix, it identifies respective responsibilities, actions, practices, and skills needed by the various stakeholders - policymakers, facility managers, providers, communities, families, and women - whose actions can help to ensure that women and newborns receive appropriate, effective, and timely care during pregnancy, Labor, childbirth and the postpartum period. It is less common in many developing countries including Ethiopia. For example, $16.5 \%$ of women in Robe woreda,Oromia region, $22 \%$ of women in northern Ethiopia Adigrat town, and $17 \%$ in Southern Ethiopia were prepared for birth and its complication, $27.5 \%$ in Northern Nigeria, $26.5 \%$ in rural Nigeria and $55 \%$ of the respondents had made advance arrangements in Kenya, one hundred forty-nine mothers (47.8\%) in Indore City, India were well-prepared [10-16].

Despite the fact that; $\mathrm{BP} / \mathrm{CR}$ is essential for further improvement of maternal and child health and prevention of maternal deaths, there is no study on the status of birth preparedness and complication readiness in the hospital. Therefore, this paper was aimed to assess knowledge and practices on birth preparedness and complication readiness and related factors among antenatal clients in Federal Police Referral Hospital. The results of the study will provide valuable information for design of possible programs and interventions to improve maternal and neonatal health. And also serve as baseline information for further study.

\section{Methods}

Institution based cross-Sectional study was conducted from September 14, 2014- October, 242014 women Ante Natal Care (ANC) in Federal Referral police hospital (FPRH), Addis Ababa. Maternal and child health (MCH) service is one of the services given in the hospital. A total of 1066 new pregnant women have been attended ANC service 2013/14 [7].

All pregnant women attending ANC in FPRH were taken as source population and the study population were pregnant mothers who were ANC attendants during study period. Inclusion criteria was all pregnant women who were ANC attendants during the study period who were willing to be interview and exclusion criteria was pregnant women who were not mentally and physically capable as well as who interviewed and came repeatedly during study period.

Sample size was determined by using the formula for single population proportion. Accordingly, a total of 224 
women were taken as sample based on $95 \%$ Confidence interval and $5 \%$ margin of error, $16 \%$ proportion of birth preparedness and complication readiness among women in Oromia Region previous study [10], considering non response of $10 \%$.

A woman was considered knowledgeable on key danger signs of pregnancy, if she can mention at least three of the four key danger signs for pregnancy (vaginal bleeding, swollen hands/face blurred vision and water breaks without labor) spontaneously. A woman was considered knowledgeable on key danger signs of labor/childbirth, if she can mention at least three of the key four danger signs for labor/childbirth (severe vaginal bleeding, prolonged labor (>12huors), convulsion and retained placenta) spontaneously. A woman was considered knowledgeable on key danger signs of postpartum, if she can mention at least two of the three key danger signs for postpartum (severe vaginal bleeding, foul-smelling vaginal discharge and high fever) spontaneously. These variables for key danger signs were transformed on SPSS into a single variable, as indicated above to be considered as knowledgeable.

A woman was considered as prepared for birth and its complication if she reported that she identified place of delivery, saved money, identify skilled provider at birth, identified a means of transport to place of childbirth, prepared material for safe delivery and identify danger sign. These six variables were transformed on SPSS into a single variable, that is "birth preparedness and complication readiness" which was identified whether the woman prepared for birth and its complication or not. Then those mothers who followed at least four of the six BP/CR components were considered as "prepared for birth and its complication". The remaining women were considered as "not prepared for birth and its complication".

Pre-tested structured questionnaires were used adapted from monitoring birth preparedness and complication readiness, tools and indicators for maternal and newborn health [9]. It prepared in English and translated to Amharic and the Amharic version was used by data collectors during interview. Five BSc nurse students were collected the data after having two days training. Two supervisors with BSc nurse background were supervised the data collectors.Filled questionnaires were checked daily for completeness, legibility and consistency.

Concerning ethical issue, official letter was obtained from Ethiopian Police University College (EPUC) research institute and permission was secured from FPRH officials. Informed verbal consent was obtained from each respondent after explaining the objective and procedures of the study and the information was kept confidential. Data was analyzed with SPSS version 20. Different rates, as well as relevant association were computed to see statistical significant.Multiple logistic regression analysis was also done to control for possible confounding variables. P-value less than 0.05 were taken as a cut of point to declare significant association.

\section{Result}

\subsection{Socio-demographic Characteristics of Respondent}

Data were obtained from 224 mothers, yielding response rate $100 \%$. The age of respondent were ranging from 15-34 years with the mean age was 24 years. Majority of the respondents 216(96.4\%) were Married, 142(63.4\%) of them were Orthodox, 117(52.2\%) Government employee, $176(78.5 \%)$ of them were secondary school and above and $115(51.3 \%)$ of them had pregnancy of 2-3 times (table 1 ).

\subsection{Knowledge of Respondent About Key Danger Signs for Pregnancy, Labor/Child Birth and Post-Partum}

Out of the 224 respondents $152(67.8 \%)$ of the respondents considered as knowledgeable for danger signs of pregnancy, $140(62.1 \%)$ of the respondents considered as knowledgeable danger signs for labor/childbirth and 118 $(52.2 \%)$ mentioned at least two of the three key danger signs for postpartum (fig 1).

Table 1. Socio demographic characteristics of respondents. A/A, FPRH, October 2014.

\begin{tabular}{|c|c|c|}
\hline Variable(224) & Frequency & $\%$ \\
\hline \multicolumn{3}{|l|}{ Age of respondent } \\
\hline$<20$ & 18 & 8 \\
\hline $20-29$ & 170 & 75.9 \\
\hline $30-34$ & 36 & 16.1 \\
\hline \multicolumn{3}{|l|}{ Marital status } \\
\hline Married & 216 & 96.4 \\
\hline Single & 2 & 0.9 \\
\hline Separated /Widowed & 2 & 0.9 \\
\hline Divorce & 4 & 1.8 \\
\hline \multicolumn{3}{|l|}{ Religion } \\
\hline Orthodox & 142 & 63.4 \\
\hline Catholic & 8 & 3.6 \\
\hline Muslim & 31 & 13.8 \\
\hline Protestant & 43 & 19.2 \\
\hline \multicolumn{3}{|l|}{ Occupation } \\
\hline House wife & 62 & 27.7 \\
\hline Gov. employee & 117 & 52.2 \\
\hline Private employee & 45 & 20.1 \\
\hline \multicolumn{3}{|l|}{ Education } \\
\hline No formal education & 5 & 2.2 \\
\hline Primary & 43 & 19.2 \\
\hline Secondary & 113 & 50.4 \\
\hline Above secondary & 63 & 28.1 \\
\hline \multicolumn{3}{|c|}{ Monthly income in $\operatorname{Birr}(n=224)$} \\
\hline Less than 500 & 5 & 2.2 \\
\hline $501-1000$ & 60 & 26.8 \\
\hline$>1000$ & 159 & 71.0 \\
\hline \multicolumn{3}{|l|}{ Gravidity $(n=224)$} \\
\hline 1 & 101 & 45.1 \\
\hline $2-3$ & 115 & 51.3 \\
\hline$>4$ & 8 & 3.6 \\
\hline
\end{tabular}




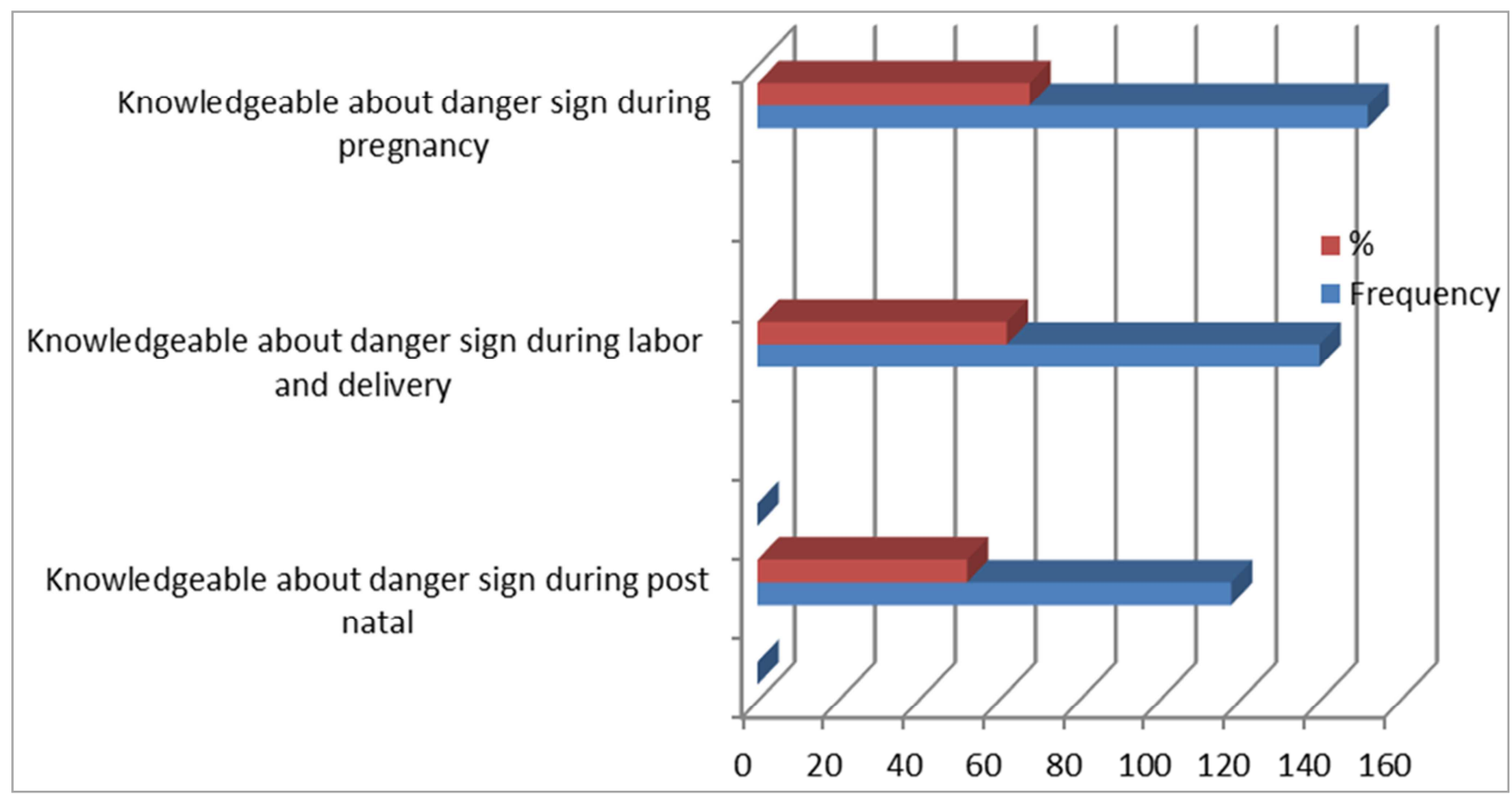

Fig. 1. Knowledge of ANC clients on danger sign of pregnancy, labor/child birth and post natal. A/A. FPRH. Oct, 2014.

Table 2. Distribution of women prepared for birth and its complication to some socio-demographic and obstetric characteristics. A/A, FPRH, October 2014

\begin{tabular}{|c|c|c|}
\hline \multirow[t]{2}{*}{ Variable $(n=126)$} & \multicolumn{2}{|c|}{$\begin{array}{l}\text { Preparedness for birth and its } \\
\text { complication }\end{array}$} \\
\hline & Frequency & Percentage \\
\hline \multicolumn{3}{|l|}{ Age of respondent } \\
\hline$<20$ & 6 & 4.8 \\
\hline $20-29$ & 97 & 76.9 \\
\hline $30-34$ & 23 & 18.3 \\
\hline \multicolumn{3}{|l|}{ Marital status } \\
\hline Married & 122 & 96.8 \\
\hline Single & 1 & 0.8 \\
\hline Separated / Divorce & 1 & 0.8 \\
\hline Widowed & 2 & 1.6 \\
\hline \multicolumn{3}{|l|}{ Religion } \\
\hline Orthodox & 83 & 65.8 \\
\hline Catholic & 2 & 1.6 \\
\hline Muslim & 18 & 14.3 \\
\hline Protestant & 23 & 18.3 \\
\hline \multicolumn{3}{|l|}{ Occupation } \\
\hline House wife & 35 & 27.8 \\
\hline Gov. employee & 65 & 51.6 \\
\hline Private employee & 26 & 20.6 \\
\hline \multicolumn{3}{|l|}{ Education } \\
\hline No formal education & 5 & 4 \\
\hline Primary & 25 & 19.8 \\
\hline Secondary & 64 & 50.8 \\
\hline Above secondary & 32 & 25.4 \\
\hline \multicolumn{3}{|l|}{ Gravidity } \\
\hline 1 & 49 & 38.9 \\
\hline $2-3$ & 72 & 57.1 \\
\hline$>4$ & 5 & 4 \\
\hline
\end{tabular}

\subsection{Birth Preparedness and Complication Readiness and Influencing Factors}

About $126(56.3 \%)$ of the women were considered as prepared for birth and its complication. Of these 97(76.9\%) were age of 20-29 years, 72(57.1\%) had pregnancy of 2-3(table 2). In bivariate analysis maternal age was significantly associated with birth preparedness and complication readiness. Mothers whose age less than 20 years wereabout 3times more likely to prepare for birth and it's complication than mothers with age 20 years and above(COR $=3.5,95 \%$ CI: $1.07,11.66$ ) other socio demographic factor did not show significant association with birth preparedness and complication readiness.

Knowledge on the key danger sign of obstetric complications was also significantly associated with birth preparedness and complication readiness in crude analysis. Mothers who knew the key danger sign of pregnancy, child birth andpost-partum were almost three times more likely to be prepared for birth and its complications than mothers who didn't know respectively $(\mathrm{COR}=2.61,95 \% \mathrm{CI}: 1.47,4.65)$; $(\mathrm{COR}=2.72,95 \% \mathrm{CI}: 1.56,4.74)$ and $(\mathrm{COR}=2.66,95 \% \mathrm{CI}$ : $1.54,4.53)$. When the age of the client from socio demographic variables; knowledge on key danger signs of pregnancy, labor and post-partum were adjusted no one significantly associated with birth preparedness and complication readiness. 
Table 3. Socio-demographic and obstetric factors influencing birth preparedness and complication readiness adjusted for confounding variables, in FPRH, Oct, 2014.

\begin{tabular}{|c|c|c|c|c|}
\hline \multirow[t]{2}{*}{ Variable } & \multicolumn{2}{|c|}{$\begin{array}{l}\text { Birth preparedness and } \\
\text { complication readiness }\end{array}$} & \multirow[t]{2}{*}{$\operatorname{COR}(95 \% \mathrm{CI})$} & \multirow[t]{2}{*}{$\operatorname{AOR}(95 \% \mathrm{CI})$} \\
\hline & Yes & No & & \\
\hline \multicolumn{5}{|l|}{ Age in yrs } \\
\hline$*<20$ & 6 & 12 & $\begin{array}{l}* 3.5(1.07- \\
11.66)\end{array}$ & \multirow[t]{3}{*}{$0.63(0.33-1.22)$} \\
\hline $20-29$ & 97 & 73 & $1.3(0.63-2.8)$ & \\
\hline $30-39$ & 23 & 13 & 1.00 & \\
\hline \multicolumn{5}{|c|}{ knowledgeable on key danger signs of pregnancy } \\
\hline Yes & 97 & 55 & $\begin{array}{l}* * 2.61(1.47-4 . \\
65)\end{array}$ & \multirow[t]{2}{*}{$1.7(0.82-3.49)$} \\
\hline No & 29 & 43 & 1.00 & \\
\hline \multicolumn{5}{|c|}{ knowledgeable on key danger signs of labor/childbirth $(n=223)$} \\
\hline Yes & 91 & 49 & $\begin{array}{l}* * 2.72(1.56-4 \\
74)\end{array}$ & \multirow[t]{2}{*}{$1.4(0.68-3.2)$} \\
\hline No & 34 & 49 & 1.00 & \\
\hline \multicolumn{5}{|c|}{ knowledgeable on key danger signs of postpartum $=223$} \\
\hline Yes & 81 & 37 & $\begin{array}{l}* * * 2.66(1.54-4 \\
.53)\end{array}$ & \multirow[t]{2}{*}{$1.4(0.6-3.27)$} \\
\hline No & 45 & 60 & 1.00 & \\
\hline
\end{tabular}

*Statistically significant at $\mathrm{p}<0.05$. ${ }^{*}$ Statistically significant at $* * * \mathrm{p}<0.01$ in the crude analysis

\section{Discussion}

Every woman needs to be aware of the key danger signs of obstetric complications during pregnancy, delivery and the postpartum period. Poor awareness of women will have a possible high chance of poor outcome of pregnancy. This could be attributed to presence or absence of relevant intervention to promote birth preparedness and complication as well as utilization of health care service $[2,3]$.

In this study the proportion of respondents considered as knowledgeable for key dangerous signs were 152(67.8\%), 140 (62.1\%), 118 (52.2\%) during pregnancy, delivery, and postpartum respectively. This finding was higher than the finding on Ethiopian Demography and health survey (EDHS) 2011, among women who were informed of signs of pregnancy complications at an ANC visit for their last live birth, almost half (48\%) as single variable, this might be because of the EDHS finding is national from various group and region whereas this finding was the finding from specific area. Also the finding was extremely different from study done in Jimma zone Ethiopia, in a community based study only $227(6.3 \%)$ were able to spontaneously mention all the three key danger signs of pregnancy: $133(3.7 \%)$, were able to mention all the four key danger signs of delivery and child birth spontaneously $[3,8]$.

Birth preparedness and complication readiness is less common in many developing countries including Ethiopia. In this study about $126(56.3 \%)$ of the women was considered as prepared for birth and its complication. This finding was found to be three fold more than the finding in Robe woreda Oromia region which was $16.5 \%$ of women, about $22 \%$ of the respondents were prepared Adigrat town in northern Ethiopia, and $17 \%$ in Southern Ethiopia, $23.3 \%$ of women in Jimmazone Ethiopia, were prepared for birth and its complication, $27.5 \%$ in Northern Nigeria, $26.5 \%$ in rural Nigeria this might because of this study was carried out in center of the city where better access of health care and information is available. And a bit higher than the study done in Indore City, India, where 149 (47.8\%) mothers were well-prepared; almost similar with the finding $55 \%$ of women in Nairobi Kenya [10-16, 18].

Knowledge of danger signs of obstetric complication will ultimately empower them and their families to make prompt decisions to seek care from skilled birth attendants (9).In this study maternal knowledge on key danger signs of pregnancy labor and delivery $(\mathrm{COR}=2.72,95 \% \mathrm{CI}: 1.56,4.74)$ was significantly associated with birth preparedness and complication readiness. This finding found to be similar with the find in Jimma zone Ethiopia where women who knew all the four key danger signs during labor and delivery were more likely to be prepared for birth and its complications $(\mathrm{OR}=2.04$; $95 \%$ CI: $1.22,3.39)$ [18].

\section{Conclusion and Recommendation}

In his study about $56.3 \%$ women were prepared for birth and its complication which is relatively fair, however since the study has been done in center of the city where better access of health care and information is available it was expected more.Knowledge of key dangers signs of pregnancy, labor and delivery and postpartum were found to be the main factors affecting birth preparedness and complication readiness. Improving ANC education on $\mathrm{BP} / \mathrm{CR}$, giving special emphasis to comprehensive knowledge of key danger signs is recommended.

\section{Acknowledgment}

The author would like to thank all the study participants, data collectors, supervisors and FPRH authorities for their cooperation in any process of this study.

\section{References}

[1] WHO, UNICEF, UNFPA. Trends in maternal mortality: 1990 to 2013 Estimates by WHO, UNICEF, UNFPA, The World Bank and the United Nations Population Division. Available atapps.who.int/iris/.../9789241507226_eng.pdf.

[2] WHO. Reduction of Maternal mortality joint WHO/UNFPA/UNICEF/World Bank Statement. WHO, $\begin{array}{lll}\text { Geneva, 2010.Available at } & \end{array}$ http/www.who.inf/reproductive.

[3] Central Statistical Agency: Ethiopia, Demographic and Health Survey 2011. Maryland, USA: Addis Ababa, Ethiopia, ICF International, Calverton; 2012.

[4] Central Statistical Agency (CSA) [Ethiopia], ORC Macro. Ethiopia Demographic and Health Survey 2000. Addis Ababa, Ethiopia, and Calverton, Maryland, USA: CSA and ORCMacro.2001. Google Scholar. 
[5] Central Statistical Agency (CSA) [Ethiopia], ORC Macro. Ethiopia Demographic and Health Survey 2000. Addis Ababa, Ethiopia and Calverton, Maryland, USA: CSA and ORC Macro.2006. Google Scholar.

[6] United Nations: The Millennium Development Goals Report; World Health Organization (WHO) and UN Development Programme (7. UNDP). 2010. UN MDG Database (mdgs.un.org); MDG Monitor Website (http://www. mdgmonitor.org).

[7] JHPIEGO, Monitoring Birth preparedness and complication readiness, tools and indicatorsfor maternal and newborn health. Johns Hopkins, Bloomberg School of Public Health, Center for Communication Programs, Family Care International; 2004. http://pdf.dec.org/pdf- docs/PNADA619.pdf.

[8] The White Ribbon Alliance for Safe Motherhood/India. Saving Mother's Lives: what works, a field guide for implementing best practices in safe motherhood. Best Practices Sub-committee, April 11, 2010.

[9] JHIPEGO, Maternal and neonatal program. Birth preparedness and complication readiness: AMatrix of shared responsibilities. MNH; 2001. PubMed | Google Scholar.

[10] Muhammedawel K, and Mesfin A. Birth preparedness and complication readiness in Robe Woreda, Arsi Zone, Oromia Region, Central Ethiopia. Kaso and Addisse Reproductive Health. 2014, 11:55. http://www.reproductive-health-journal.com/content/11/1/55.

[11] Hiluf M, fantahun M. Birth Preparedness and Complication
Readiness among women inadigrat town, North Ethiopia. Ethiopia. J. health Dev. 7, 22(1): 14-20.

[12] Hailu M, Gebremariam A, Alemseged F, Deribe K: birth preparedness and complication readiness among pregnant women in Southern Ethiopia. PLoS One 2011, 6(6):e21432.doi:10.1371/journal.pone.0021432.

[13] Iyasu Z, Abubakar I, Galadanci H, Aliyu M: Birth preparedness, complication readiness and fathers' participation in maternity care in a Northern Nigerian Community. Afr J Reprod Health 2010, 14(1):21-32.

[14] Pembe AB, Urassa DP, Carlstedt A, etel. Rural Tanzanian Women's awareness of danger signs of obstetric complication. BMC Pregnancy and Childbirth 2009, 9:12. http://www.biomedcentral.com/1471-2393/9/12,accessed.

[15] Mutiso SM; Qureshizkinuthia J. Birth preparedness among antenatal clients at Kenyattanational Hospital Nairobi, Kenya, East African Medical Jornal Vol. 85(6) 2008: PP, 275 -283.

[16] Agarwal S, Sethi V, Srivastava K, K. Jha P and Abdulalah H Birth Preparedness andComplication Readiness among Slum Women in Indore City, India. J Health Popul Nutr. Aug; 28(4):383-391.

[17] FPRH. Health Management Information System (HMIS) department. A/A.2013/14.

[18] Tura G, Mesganaw D, Afework F etel. Factors affecting birth preparedness and Complication readiness at the different levels by applying multilevel analysis of community based study in Jimma zone. Pan Afr Med J. 2014; 19: 272. 